\title{
CONTEMPORARY PROBLEMS IN MATHEMATICAL TEACHING AND STAFFING
}

$I^{\mathrm{T}}$ is now generally recognized that, in the drive to meet the modern needs of Great Britain on the industrial side, many new problems are emerging in relation to the creation of the necessary scientific and technological personnel. Two of these, in particular, arise out of the comparatively recent appreciation of the fact that mathematics has moved into a central position in the study and development both of science and of technology. There is scarcely a sector of these that is not leaning more and more on mathematical techniques. This, therefore, poses a new task to the mathematical profession; and those who are concerned that it should be effectively carried out can see at once the two problems that stand out sharply. One relates to the content and mode of presentation of the subject-matter that must be taught both at school and at university. The other is concerned with the supply of teachers with mathe. matical qualities adequate to the new tasks that face the profession. It is therefore not at all surprising that at almost every scientific gathering these two issues come up for discussion.

Section A (Mathematics) jointly with Section L (Education) of the British Association meeting in Glasgow devoted the whole morning of September 2 to precisely these questions. Mr. W. J. Langford, president of the Mathematical Association, presented an interesting survey of the history of the movement for reform of mathematical teaching at schools, from the days when "Euclid" constituted the mathematical Bible, to the modern many-sided approach, where it is possible to dip into the calculus at a relatively early stage. Now, however, the problem has sharpened in another way. As the universities strive to carry their final-year students right to the frontiers of knowledge in this rapidly developing field, the schools are expected to keep pace with what must inevitably be a rising standard of entry, unless, indeed, the period of university study is itself correspondingly lengthened; and this is occurring at a time when apparently less than one-third of those engaged in the teaching of mathematics at school have specific qualifications in this subject. Mr. Langford indicated the possibility that in the near future there may be established an institute of mathematics, comparable to the engineering institutes, which might offer a qualification capable of being acquired by teachers of mathematics who have not reached graduate standard, but are willing to improve their knowledge of the subject presumably while still engaged in teaching.

The dangers inherent in the present position were sharply underlined by Prof. L. Rosenhead, who made a searching survey of our present resources in mathe. matical personnel, in order to examine how far it might be possible by 1970 to attain to double the number of mathematical teachers that were available in 1955, as hoped for in the present plans. Whether it is consciously visualized or not, for this purpose school and university education is a single process, so that in the last resort the problem of the universities and the colleges in this matter of scientific and technological supply is intimately bound up with what happens in the primary schools. In the U.S.S.R. this has long been recognized, and they are now reaping the advantages of planning on an integrated basis. In Britain, teachers of arithmetic at the primary stage have in general no mathematical knowledge ; while again, at the later stages, the potential mathematical interest of the children is often destroyed by the inability of the teacher to awaken the interest of the pupil by opening up to view the wider horizons. At the present moment, there is a frantic search for mathematical school teachers. Since quite a large proportion of those who actually teach the subject have almost negligible qualifications in it, already in some girls' schools the teaching of some branches of mathematics has been given up. In such circumstances, deterioration must inevitably set in.

Prof. Rosenhead asserted that over the past twenty years there had been a definite fall in the level of preparedness at university entry, and if university standards are to be maintained, as they must, the proportion of failures is bound to increase. As a temporary measure he suggested an expansion of the present trend towards the grouping of schools on an area basis for such special teaching, and that no one should be allowed to remain in the sixth form for more than two years. Such expedients, of course, clearly do not get down to the root of the matter, which is the simple fact that those who take high mathematical qualifications at the university are now being attracted elsewhere than into the teaching profession. Industry has within the past decade become conscious of the fact that it is able to use highly skilled mathematicians of almost all kinds-both pure and applied, analysts and computing machine programmers-and the nature of the tasks such mathematicians encounter seem to appeal to them more strongly than the work of the teaching profession. Over and above all this, of course, is the hard fact that salaries are higher in industry. It has therefore become the exception rather than the rule to find mathematical students who are keen on teaching as a career. A generation ago the converse was true. It seems to follow that the standard of mathematical qualification within the teaching profession must deteriorate, so that industry itself will finally begin to experience the effect of the shortage which it is itself helping to create. The fact is simply that there is too small an output of mathematicians to meet the prevailing needs, and the particular advantages that industry can offer tend to canalize those who are produced into that field. In such a situation, the decision as to which is the greater social priority is being left to blind economic forces. As both Mr. Langford and Prof. Rosenhead stressed. in present circumstances the coming generation cannot possibly reach a standard of achievement in keeping with its native ability.

Again the content of, and the approach to, mathematical teaching came under very sharp review. $\mathrm{Mr}$. Langford had pinpointed the successive advances 
that had been made in school teaching since the "Euclidean" days, and the gradual recognition that mathematics is a single co-ordinated subject, where it is possible to introduce such topics as analytical geometry and calculus long before algebra and geometry had been carried to the limits of school achievement.

Prof. H. Levy dealt mainly with the teaching of applied mathematics, at the university-level, to students of various faculties. He pressed the view that diagrams on paper and blackboard should be realistically seen for what they are-simplified physical 'models' in chalk or carbon particles of actual things. Already, even at this stage, irrelevant elements in the medley of events in the real world have been dropped out, and from this rather grotesque model, sticking to an almost flat surface, it becomes relatively easy for the student to make the mental abstractions we call lines, curves and points. Mathematics, he asserted, deals in the first instance only with these abstractions, and in this way the mathematician sets out to develop a logical deductive system in place of the actual physical process that is being studied. The laws of Nature-Newton's laws, for example - are extracted and abstracted from the medley of real objective events 'out there', and enter as mere mathematical assumptions into the logical analysis. It is important for a student to see this clearly in order to undermine the 'mystique' of a mathematically derived formula, and to underline the fact that its validity finally rests on verification by observation or experiment, and not merely on logic. In all this, imagination plays a very important part. To construct the appropriate 'model' on paper or blackboard, from the physical sequence of events, requires a considerable effort of the imagination; just as the sense of logical conviction itself rests on a mental scrutiny of imagined alternatives at each step of a proof.

From this point of view Prof. Levy sharply criticized the usual sets of examples and exercises in text-books, in which the author himself has already made the principal geometrical abstraction, expressing it through the phrasing of the question, while the dynamical principle that is to be used in the logic is made obvious from the place of the example in the text-book. While not undervaluing that kind of 'drill', he insisted that teaching and learning are simply two aspects of one process in which both teacher and student are engaged. It follows from this that the teacher must be seen by the student to wrestle with a problem, and, if necessary, to be beaten. The problem must be real, and not a faked-up one designed to come out. Preferably, it should be brought by the student out of his own experience so that the successive steps in forming the abstrac. tions may become apparent. Familiarity with both geometrieal and dynamical abstractions plays a significant part in pointing the way towards this reduction of actual physical problems to those of logic. Finally, the precise verbal formulation of the problem in concise terms, as it would appear in a text-book, is itself a crucial educational step. Prof. Levy concluded by stating that in his view it was desirable that every mathematical department should have available as many bits of machines as possible, in order that the student should take them to pieces and re-assemble them, and so seek to isolate the dynamical factors that appear to be in operation during their functioning. In this way the geometrical and dynamical abstractions that require to be made in order to analyse the process from the mathematical point of view would become apparent. This kind of training, consciously applied and consciously appreciated by the student, was essential if he was to play his part qua mathematician in modern industry.

Dr. E. A. Maxwell turned to the problem of the teaching of pure mathematics, and in particular he raised the question by what process could the student be encouraged from the beginning to appreciate the importance of rigorous and accurate thinking, and, as part of this, the specific limitations under which the theorems he was using were valid. To this end he stressed the educational value of using the method of contradiction, in a direct form, by 'proving' a number of propositions of the $2=1$ type, for the purpose of intriguing the student in the first place. As a consequence, his interest is enlisted in discovering where and how precisely the limitations of the method used have been overstepped. This he illustrated with a variety of examples from a wide range of mathematics. An excellent discussion followed a most interesting morning session.

\section{PHYSIOLOGY AS AN EDUCATION AND AS A CAREER}

$\underset{\text { Briti }}{\mathrm{A}}$ JOINT session of Section I (Physiology/Biochemistry) and Section L (Education) of the British Association and of the Physiological Society, held in the Institute of Physiology, University of Glasgow, on September 3, was devoted to a discussion of "Physiology as an Education and as a Career".

In the absence of Prof. A. V. Hill his introductory remarks were read, with evident sympathy and signal effect, by one of his former junior colleagues, Prof. R. W. Gerard, of the Department of Physiology, University of Michigan. Prof. Hill began by recalling what he had said on this topic on several occasions from the 1920's onwards. In these he emphasized the need to free physiology from the bedside attachment of its earlier years and allow it to come in its own right to full stature, as the interpretation of the mechanisms and integrations of normal life. Thus physiology would be brought into a wider service of mankind in the modern fully industrialized State. It has become necessary to spread into now fields the knowledge of the "exquisite structure of the body" and the proper understanding of its functional capabilities and limitations. In all this there is need for first-class brains because in the biological field the data are much more intractable than are those in the inorganic field. This battle for the status of physiology in its own right is slowly being won. Much could be done by capturing early the imagination and interest of the young and securing recruits by means of practical demonstrations and teaching in the schools. 